\title{
Significados y debates sobre la adherencia a los tratamientos antirretrovirales entre jóvenes activistas en el área metropolitana de Buenos Aires
}

\author{
TOMAS KIERSZENOWICZ \\ Universidad de Buenos Aires, Buenos Aires, Argentina \\ tomaskier5@gmail.com
}

DOI 10.11606/issn.2316-9133.v29i2pe171966

\begin{abstract}
resumen Con el advenimiento de las terapias antirretrovirales altamente activas que desde mediados de la década de 1990 redujeron las enfermedades oportunistas y la mortalidad asociada al VIH reconfigurando el escenario de las respuestas políticas y asistenciales frente a la epidemia del VIH, la "adherencia" a los tratamientos pasó a ser una cuestión central de los abordajes médico-institucionales. En este contexto, han cumplido un rol significativo las organizaciones de la sociedad civil en articulación con organismos y agencias de cooperación internacionales. En este artículo se analizan los significados y sentidos expresados por activistas de la Red Argentina de Jóvenes y Adolescentes Positivos del Área Metropolitana de Buenos Aires en torno de los tratamientos de larga duración, presentando además cómo el problema de la "adherencia" se debate en ocasión de distintos eventos y actividades institucionales. Para esta investigación se implementó un abordaje etnográfico con participación en las actividades de la red, entrevistas a activistas y análisis de fuentes secundarias. Los diversos sentidos y prácticas que despliegan los activistas nos aproximan a los límites del discurso médico dominante que tiende a reducir la "adherencia" a la actitud racional o irracional del paciente.
\end{abstract}

palabras clave VIH. Jóvenes. Adherencia. Activismo. Argentina.

Meanings and debates on adhering to the antiretroviral therapy among young activists in the metropolitan area of Buenos Aires

abstract The "adherence" to treatments became a central issue in medicalinstitutional approaches and shaped the political and healthcare response to HIV since the breakthrough of highly active antiretroviral therapies that has reduced the associated opportunistic diseases and mortality to HIV as of mid-1990s. Civil society organizations have taken critical part in this context through the partnership with international cooperation agencies. This article analyzes the meanings given by activists from the Argentinian Network of Positive Young People and Adolescents in of the Metropolitan 
Area of Buenos Aires regarding long-term treatments, showing how the problem of "adherence" is discussed in organizational activities. It is based on the ethnographic approach with participation in network activities, interviews with activists and source analysis. The senses and practices that activists produce bring us closer to the limits of the dominant medical discourse that tends to reduce "adherence" to the (ir)rational attitude of the patient.

Keywords HIV. Young people. Adherence. Activism. Argentina.

\section{Significados e debates sobre a adesão às terapias antirretrovirais entre}

\section{jovens ativistas na área metropolitana de Buenos Aires}

resumo Com o advento de terapias antirretrovirais altamente ativas que reduziram doenças oportunistas e mortalidade associadas ao HIV desde meados dos anos 90, reconfigurando o cenário de respostas políticas e de saúde à epidemia de HIV, "aderência" a tratamentos tornou-se uma questão central nas abordagens médico-institucionais. Nesse contexto, as organizações da sociedade civil têm desempenhado um papel significativo na coordenação com agências e agências de cooperação internacional. Este artigo analisa os significados e significados expressos por ativistas da Rede Argentina de Jovens e Adolescentes Positivos da Região Metropolitana de Buenos Aires em torno de tratamentos de longo prazo, apresentando também como o problema de "aderência" é debatida em diferentes atividades institucionais. Para esta pesquisa foi implementada uma abordagem etnográfica com participação em atividades em rede, entrevistas com ativistas e análise de fontes secundárias. Os sentidos e práticas dos ativistas nos aproximam aos limites do discurso médico dominante que tende a reduzir a aderência à atitude (ir)racional do paciente.

palavras-chave HIV. Jovens. Aderência. Ativismo. Argentina.

\section{Introducción}

Después de mediados de la década de 1990, la medicina del Sida se modificó sustancialmente con el desarrollo de terapias antirretrovirales que mejoraron el pronóstico de infección de VIH de las personas afectadas designándose, a partir de entonces, al Sida como enfermedad transmisible crónica y transformando la "adherencia" a los tratamientos en una cuestión central de los abordajes médico-institucionales. Estos y otros desarrollos tecno-científicos reconfiguraron el escenario de las respuestas políticas y asistenciales frente a la epidemia a nivel global.

Como plantean Margulies, Barber y Recoder (2006: 286-287), "el proceso de "normalización" del sida y de las condiciones de vida con el virus asociado a las terapias antirretrovirales se ha correspondido con una construcción de representaciones y prácticas sanitarias (...) con un énfasis creciente en el manejo responsable de los riesgos a través del "cuidado de sí y de otros"”. En este sentido, la "adherencia" ha sido presentada por la biomedicina como la "actitud de cumplimiento o incumplimiento del tratamiento" tomando 
como referencia las acciones que los afectados realizan con el fin de mejorar su estado de salud en coincidencia con las prescripciones médicas (op.cit.).

La Dirección Nacional de Sida y Enfermedades de Transmisión Sexual (DNSyETS 2019a) estima en 139.000 las personas infectadas por el virus hasta 2018 en Argentina. Anualmente se notifica un promedio de 5.135 nuevos casos, de los cuales el 32\% corresponden al Área Metropolitana de Buenos Aires (AMBA). Desde 2005 se registra un incremento anual en la proporción de notificaciones de casos de VIH de varones entre 15 y 29 años. Por el contrario, el grupo de mujeres de 15 a 29 ha disminuido en la proporción del total de los casos notificados desde 2005.

Entre los mayores de 15 años, la principal vía de transmisión al nivel nacional son las relaciones sexuales no protegidas (DNSyETS 2019a). Atendiendo a las infecciones reportadas entre 2016 y 2018 en varones, el 58\% se produjeron a partir de relaciones con otro varón y el $41 \%$ con mujeres. Las notificaciones de la ciudad de Bueno Aires entre 2003 y 2015 muestran una mayor paridad: el $45.47 \%$ se produjeron en el marco de relaciones con otro varón y el $46.57 \%$ con una mujer. En cuanto a las mujeres, se informa como vía principal de transmisión las relaciones heterosexuales sin protección (DNSyETS 2019a, CSSSeI 2018).

Las organizaciones de la sociedad civil han cumplido un rol significativo no sólo en la demanda de tratamientos médicos al Estado, sino también en las intervenciones preventivo-asistenciales y en el acompañamiento a las personas viviendo con VIH (PVV). Desde mediados de la década de 1990, estas organizaciones accedieron al financiamiento de organismos y agencias de cooperación internacionales para la realización de nuevas intervenciones dirigidas a la promoción de prácticas preventivas del VIH y la formación de PVV como "educadores" en el "campo del asesoramiento, apoyo y tratamiento relacionados con el VIH/Sida” (ONUSIDA 2000).

Este artículo se desprende de los resultados de la investigación llevada a cabo para mi Tesis de Licenciatura en Ciencias Antropológicas realizada en el marco institucional de la Red Argentina de Jóvenes y Adolescentes Positivos (RAJAP) entre agosto 2015 y junio 2016 en la cual analicé los "itinerarios de atención y cuidado" (ALVES 2015) de integrantes de la RAJAP con el objeto de explicar cómo articulan sus prácticas de activismo con la experiencia de "ser joven" y vivir con VIH. Para el trabajo de campo se aplicó una perspectiva etnográfica, entendiéndola en tanto "mirada analítica que trata de aprehender una porción del mundo social a través de un análisis centrado estratégicamente en las perspectivas de los actores y tendiente a integrarlas coherentemente en sus productos" (BALBI 2010: 172).

Como principal estrategia metodológica, privilegié la observación con participación en las actividades de la red, complementando con entrevistas a activistas, análisis de fuentes secundarias y el seguimiento en las redes sociales. El material etnográfico que se analiza en este artículo proviene de la sistematización de registros de campo y de la reconstrucción de testimonios e intercambios en las actividades de la red y entrevistas en profundidad a tres activistas de la RAJAP. 
Conformada en el año 2010, la RAJAP se caracteriza por ser un espacio de participación, apoyo e intercambio dirigido y organizado exclusivamente por jóvenes que viven con VIH a nivel nacional. La RAJAP se gestó a partir del apoyo técnico y económico que brindaron agencias de cooperación internacional como ONUSIDA, UNICEF y UNFPA y las alianzas entabladas con activistas de otras redes del activismo en VIH-Sida.

Específicamente, en este artículo analizo los significados y sentidos expresados por algunos activistas en torno de estos tratamientos de larga duración y presentaré cómo el problema de la "adherencia" se pone en juego y se debate en ocasión de distintos eventos y actividades institucionales. Recupero, además, la tensión suscitada al interior de la red cuando uno de los jóvenes decide interrumpir su tratamiento, esto es, en los términos habituales, cuando opta por "no adherir", procurando iluminar los límites de las acciones de "contención" en una organización de la sociedad civil de jóvenes con VIH.

\section{Respuestas médico políticas al VIH-Sida en Argentina}

En el año 2000, los países integrantes de la Asamblea general de las Naciones Unidas acordaron una agenda global a 2015 para el cumplimiento de los Objetivos de Desarrollo del Milenio (ODM), entre los que se indicaba como meta detener y revertir la expansión del VIH/Sida ${ }^{1}$. El monitoreo de los ODM puso en evidencia que en 2008 aproximadamente el $40 \%$ de las nuevas infecciones a nivel global se produjeron en jóvenes de entre 15 a 24 años (Naciones Unidas 2010; OMS 2010), lo que llevó a clasificar a los “jóvenes” simultáneamente como grupo "vulnerable" y "clave”, estableciéndose que para 2015 se buscaría "reducir en un 50\% el porcentaje de jóvenes de 15 a 24 años infectados” en comparación con 2008 (OMS, 2010).

Esta agenda fue actualizada en 2015 con la definición de los Objetivos de Desarrollo Sostenible (ODS), sobre los cuales se estableció una estrategia de "acción acelerada" (ONUSIDA 2016) para el período 2016-2021 que apunta a la denominada "cascada 90-9090", esto es, que $90 \%$ de las personas que viven con el VIH conozcan su estado; $90 \%$ de las personas que viven con el VIH y que conocen su infección reciban tratamiento y $90 \%$ de las personas infectadas tengan suprimida la carga viral. Argentina suscribió en 2015 a estas metas (DNSyETS 2015).

La "acción acelerada" busca "poner fin a la epidemia" (ONUSIDA 2014) focalizándose en las denominadas "poblaciones clave" (ONUSIDA 2014), entre ellas los "jóvenes y adolescentes”, entre quienes se identifican "obstáculos para el acceso significativo al tratamiento y la obtención de resultados de salud favorables" (ONUSIDA 2014). Los "adolescentes" de 15 a 19 y los "jóvenes" de 20 a 24 conforman "el grupo que corre el mayor riesgo de infección por el VIH en todos los contextos". La explicación de este "riesgo" está dada por supuestos comportamientos y prácticas (UNICEF 2019) asociadas a "estilos de vida insanos" (ORIOL ROMANÍ; CASADÓ 2014) que los expondrían al virus.

1 Página web de la Organización Mundial de la Salud visitada el 29/05/2020. Link: https://www.who.int/topics/millennium_development_goals/diseases/es/ 
Como núcleo central de la estrategia para "poner fin a la epidemia" (ONUSIDA 2014), la promoción de la "adherencia" se presenta como un objetivo importante de financiamiento de las agencias de cooperación internacional para las organizaciones de la sociedad civil. Específicamente, la "acción acelerada" señala que uno de sus "elementos de cambio" consiste en "aumentar la inversión en redes de personas que viven con el VIH" para "el apoyo de adherencia a la medicación".

Uno de los indicadores de la eficacia del tratamiento es la "indetectabilidad" del virus, la cual se produce cuando la "carga viral", es decir, la presencia del virus en sangre, es inferior a la que el análisis de los marcadores bioquímicos puede medir. Esto implica la reconstrucción del sistema inmunológico y la reducción de las probabilidades de su transmisión en relaciones sexuales sin preservativo.

A partir de una serie de estudios clínicos que pusieron de manifiesto la reducción de las probabilidades de transmisión en pacientes con carga viral indetectable (DNSyETS 2019b), en 2016 se lanzó internacionalmente la campaña "Indetectable=intransmisible" ("I=I") con el apoyo de los principales organismos y agencias de cooperación internacional con el propósito de reducir la discriminación y el estigma asociado a las transmisión del virus por parte de las personas afectadas durante relaciones sexuales desprotegidas (DNSyETS, 2019b).

En este sentido, la "adherencia" al tratamiento es una de las "intervenciones de alto impacto" que se inscribe en el denominado "modelo de prevención combinada" para "frenar a la epidemia" (ONUSIDA 2015). Forma parte de este modelo, además, las tecnologías preventivas como el preservativo y la profilaxis pre-exposición (PreP), definida como el "uso de tratamiento antirretroviral (TARV) en personas que no tienen el virus para reducir su riesgo de infección por VIH por vía sexual" (DNSyETS 2019c). En Argentina, la PreP aún no ha sido autorizada por el Ministerio de Salud y la única forma de acceder a estos es a través de "ensayos clínicos".

Las estrategias de prevención colectiva se han orientado no solo a partir de la promoción del TARV en los afectados para mantener la carga viral del virus "indetectable" y así disminuir las posibilidades de su transmisión, sino también mediante la oferta de tecnologías médicas (como PrEP) en personas que potencialmente podrían contraer la infección. Estas estrategias e intervenciones médicas se inscriben en el marco de una respuesta farmacologizada a la epidemia en la que no solo es posible "tratar" a la "enfermedad", sino también a la "salud" de aquellos considerados "en riesgo" (CLARKE et al, 2010).

\section{La conformación de la RAJAP y las organizaciones argentinas de personas con VIH}

Diversos autores han analizado el crecimiento del campo asociativo argentino en torno de diferentes temas, entre ellos, el de los derechos sexuales y reproductivos y el del VIH-Sida a partir de la recuperación democrática de 1983 y luego con la profundización de 
las condiciones de desigualdad y vulnerabilidad social producto de la implementación de políticas neoliberales en nuestro país (GRIMBERG 2003; BIAGINI 2009; PECHENY 2016). Inicialmente, fueron las organizaciones conformadas por personas del colectivo de personas lesbianas, gays, bisexuales y trans (LGBT) las que impulsaron la demanda por el reconocimiento de los derechos de quienes vivían con VIH-sida en términos de "ciudadanía" frente a un discurso estatal que en aquel momento se centraba en la responsabilidad individual de los afectados (BIAGINI; SÁNCHEZ 1995, PECHENY; MANZELLI; JONES, 2002; PECHENY 2016).

Hacia fines de la década de 1980, las PVV comenzaron a asociarse bajo sus propias organizaciones desde las cuales llevaron a cabo una diversidad de actividades que marcaron una primera etapa en la organización de la sociedad civil del VIH en Argentina. Entre estas, el acompañamiento emocional y psicológico por y para las mismas PVV, las acciones "preventivas cara a cara" (BIAGINI 2009) y las actividades reivindicativas frente al Estado en demanda de tratamientos médicos efectivos (GREGORIC 2008). En consonancia con estas demandas, se sanciona la Ley Nacional de SIDA N²3.798 (1990) y su Decreto Reglamentario $\mathrm{N}^{\circ} 1244 / 91$ a partir de los cuales se adjudica la responsabilidad de desarrollar las tareas de investigación, prevención, diagnóstico y tratamiento del SIDA al Estado argentino creándose además el Programa Nacional de Lucha contra los Retrovirus del Humano, Sida y ETS (COLAUTTI 2012).

Una nueva etapa ocurre después de mediados de la década de 1990 con el otorgamiento de financiamiento y apoyo técnico por parte de organismos internacionales y agencias de cooperación. Un año después de la creación de ONUSIDA en 1996, se establece en el país el Programa LUSIDA financiado por el Banco Mundial, con la contraparte del estado argentino para desarrollar actividades en prevención con la participación de organizaciones de la sociedad civil. La articulación con LUSIDA permitió a las organizaciones de PVV acceder a primeras líneas de financiamiento para capacitarse y ejecutar acciones "que sirvieron a la reproducción de los grupos" (GREGORIC 2007). Entre las estrategias planteadas por ONUSIDA se encuentran los "programas de educación inter pares" (ONUSIDA 2000) orientadas a formar a las PVV "como educadores inter pares en el campo del asesoramiento, apoyo y tratamiento relacionados con el VIH/Sida”.

Desde el siglo XXI, las organizaciones de PVV en Argentina encontraron en la sucesión de gobiernos progresistas (2003-2015) un interlocutor político más receptivo a sus demandas históricas. Durante este período, se sancionaron normativas para la promoción y el respeto de la salud sexual y los derechos sexuales de la población en general y de las PVV. Algunas de estas leyes incluyen apartados específicos para la población de jóvenes y adolescentes ( $\mathrm{N}^{\circ} 25.673$ y N²6.150). Entre estas normativas, se destacan la ley $\mathrm{N}^{\circ} 26.618$ de Matrimonio Igualitario y la №26.743 de Identidad de Género, las cuales materializaron demandas históricas de las organizaciones LGBT.

Es en este contexto que se institucionalizó la RAJAP en el año 2010 a partir de la propuesta de un grupo de jóvenes que, viviendo con VIH, plantearon la necesidad de "un 
espacio de encuentro, contención, soporte, capacitación y trabajo de pares creado por y para jóvenes con VIH" (Melina², 32 años, activista fundadora en entrevista realizada el 19/06/2016). La "falta de espacios de participación para jóvenes y adolescentes con VIH" (Melina) en las organizaciones de la sociedad civil fue el puntapié inicial para la gestación de la RAJAP, ya que el discurso de los jóvenes podía estar presente, pero no eran los jóvenes quienes llevaban las riendas, sino que integraban espacios liderados por sujetos "adultos". Melina se refirió a este momento de la siguiente manera:

Antes no tenías un espacio de participación política. Había muchos grupos hablando por los y las jóvenes ¿Por qué no te llevan a una persona de 25 años? (Melina, entrevista, 19/06/2016).

\section{Organización institucional de la RAJAP}

El ingreso a la red ocurre principalmente a través de profesionales de centros de salud e instituciones hospitalarias o tomando conocimiento a través de una persona cercana. Otras vías son las redes sociales y las actividades en la vía pública como la Marcha de la Diversidad Sexual.

Hugo (19 años, Coordinador de la ciudad de Buenos Aires. Entrevista realizada el 28/12/2015), me explicó que para la organización de las actividades se reconocen dos grupos etarios: "adolescentes" de entre 14 y 21 años, y “jóvenes" de entre 21 y 30 años. Aproximadamente 600 activistas integran la organización que en su mayoría son "jóvenes". La Red de Adultos Positivos (RAP) se creó como un marco de continuidad en el campo del activismo del VIH para quienes alcanzan los 30 años. Mientras que algunos optan por continuar en RAP, activistas como Melina pasaron a integrar otras organizaciones donde la "edad" no opera como un marcador que limita la participación.

Los requisitos etarios y la clasificación institucional de "adolescente” y "jóvenes" buscan introducir vínculos generacionales horizontales al interior de la organización. Los integrantes de la RAJAP emplean la noción "juventud" como categoría "auto y alter adscriptiva” (KROPFF 2010) respecto de un "otro" adulto (activistas de otras organizaciones, padres, médicos). Frente a una mirada adultocéntrica (CHAVES 2010) que los ubica como actores de cambio en un tiempo futuro, estos activistas se perciben a sí mismos como la "fuerza del presente" (Hugo). La reivindicación de "ser joven" opera fortaleciendo a los activistas en instancias habitualmente estructuradas por vínculos generacionales verticales tal como se trata de los espacios de consulta con los infectólogos. Aquí, se busca promover la "capacidad de cuestionar la hegemonía de los saberes médicos" (Hugo) para negociar y disputar sentidos e indicaciones sobre los tratamientos.

Cada uno de los "grupos de pares" distribuidos a lo largo del país se conforman como "núcleos provinciales" de la RAJAP presididos por un "coordinador/a regional". Estos referentes son elegidos por los miembros de los núcleos a partir de un proceso de votación.

\footnotetext{
${ }^{2}$ Todos los nombres han sido modoficados.
} 
A nivel nacional, la RAJAP es coordinada por tres referentes elegidos por todos los "miembros activos" durante las "asambleas" que se desarrollan anualmente en el marco del "encuentro nacional". "Miembro activo" es todo aquel que participa durante el "encuentro nacional". Para que un "miembro activo" pueda postularse al cargo de "coordinador nacional" debe ser mayor de 18 años, contar con al menos un año de activismo en la organización y tener visibilizada su condición serológica. Dicho requisito se sustenta en la importancia de que los "coordinadores nacionales" participen en medios de comunicación y movilizaciones en la vía pública para potenciar la "incidencia política" de la organización. Aunque los roles dentro de la organización conducen a la construcción de vínculos que no siempre son estructurados horizontalmente, se despliegan dispositivos que restringen la renovación de cargos.

El "encuentro nacional" es una instancia considerada esencial ya que, de no realizarse, no podría celebrarse la "asamblea", único intercambio cara a cara entre todos los miembros activos a nivel nacional. Como lo explicó Melina: "cuando se trata de destinar fondos, siempre que hay que priorizar algo, es el encuentro nacional" (entrevista del 19/06/2016). Desde su conformación, el hecho de no contar con una "personería jurídica" fue un limitante para acceder a financiamiento para sus actividades. Fue la articulación con organizaciones de la sociedad civil antecesoras en el campo del VIH-Sida, lo que le permitió "tomar prestada" una "personería jurídica" para recibir financiamiento de ONUSIDA, UNICEF y UNFPA para los "encuentros nacionales".

\section{La categoría "par" y la "contención"}

La RAJAP define como una de sus líneas de trabajo la "contención" en los denominados "espacios de pares": encuentros semanales entre jóvenes viviendo con VIH en los que se abordan las dificultades ligadas a la vida con la enfermedad. Para los activistas, "par" implica ser joven con diagnóstico de VIH. En un documento del año 2015, afirman: "La mejor forma de contenernos es compartiendo experiencias. Para un joven con VIH, no hay nada mejor que otro joven con VIH" (carpeta institucional presentada durante reuniones con representantes de entidades estatales y agencias de cooperación).

La categoría "par" es frecuentemente empleada por activistas en el campo del VIH a la vez que figura en varios documentos sobre programas, proyectos y subsidios (ONUSIDA 2000). En líneas generales, supone una relación de cercanía o afinidad entre personas, la cual puede estar dada por compartir un mismo rango etario (ej: jóvenes), género (ej: mujer), orientación sexual (ej: gay), ejercicio laboral (trabajo sexual), lugar de residencia (ej: conurbano bonaerense), entre otras. En determinadas situaciones, como en movilizaciones en la vía pública, "vivir con VIH” se presenta como la experiencia que aúna a los diversos sujetos entre sí.

Tomé contacto con la RAJAP a partir de una actividad en un "centro cultural" y en el marco de una reunión previa al inicio de mi trabajo de campo, Miguel (26 años, activista) me explicitó que los "espacios de pares" son una instancia "exclusiva para pares", es decir, 
para personas con VIH. Por ende, mi participación aquí fue restringida. Encontré que mi presencia recurrente en el resto de las actividades (reuniones operativas, actividades en la vía pública y eventos en "centros culturales") despertaba inquietudes en algunos activistas quienes me percibían como un "par", tal como ocurrió con Marcelo (activista, 27 años) durante una reunión en la sede de la RAJAP:

Marcelo: “¡Hace mucho venís acá?”

Tomas: "Hace unas semanas. Estoy trabajando en una Tesis sobre jóvenes y adolescentes con VIH".

Marcelo: “Ah, yo pensé que eras un par más”.

Distintos estudios (GREGORIC 2016; VALLE 2013; 2015) han recuperado el concepto "bio-sociabilidad" (RABINOW 1996) para dar cuenta de la formación de "grupos biosociales" en el activismo del VIH a partir de la apropiación de categorías y procesos de la biomedicina. En el caso de la RAJAP, esta biosocialidad está atravesada por marcadores etarios y generacionales. Mi participación en las actividades institucionales, con excepción de los "espacios de pares", estuvo habilitada por compartir un mismo "grupo de edad" y ser percibido por los activistas como "joven".

\section{La "adherencia" en las actividades de la RAJAP}

A lo largo del trabajo de campo, pude relevar que la cuestión de la "adherencia" a los tratamientos estaba presente en gran parte de las actividades de la RAJAP y era uno de los principales temas que se debatían entre los jóvenes. Durante interacciones que mantuve con los activistas, me expresaron distintos sentidos sobre los tratamientos. Mientras que algunos reconocen que "para poder vivir con el virus, tenés que adherir a un tratamiento" (Natalia, activista, 27 años), otros refieren "nunca tomar bien la medicación" (Natalio, activista, 22 años) o, bien, "tener que aceptar cuando un compañero no va a tomar más la medicación y no decirle "te vas a morir"' (Melina).

Un espacio de participación institucional son las "comisiones temáticas" coordinadas por un activista responsable y especializadas en los siguientes temas: "adolescencia", "comunicación”, "adherencia", "protección de derechos" e "incidencia política”. Los jóvenes de los distintos "núcleos provinciales" conforman estas "comisiones", por lo que la comunicación vía redes sociales se torna importante para el desarrollo de las tareas.

La "comisión de adherencia" tiene como propósito brindar apoyo a los miembros más recientes frente a eventuales dificultades y problemas para llevar a cabo sus tratamientos. Iziel (24 años, referente de la "comisión de adherencia”. Entrevista realizada el 17/10/2015), me explicó que desde este espacio se busca "ayudar a los chicos a que no dejen la medicación".

Uno de los proyectos que los activistas planificaban en ese tiempo se denominaba "te cuento mi adherencia”. AIDS Healthcare Foundation (AHF), una ONG estadounidense 
orientada a la prevención y la atención al VIH-Sida, había ofrecido fondos para la realización de una campaña publicitaria e impresión de materiales de difusión. Esto implicaba una revisión del contenido por parte de AHF. Durante una reunión, los activistas acordaron aprovechar esta oportunidad para realizar una "campaña de adherencia de alto impacto" destinada a difundir sus "experiencias personales con el tratamiento" (Miguel). Aquí, Hugo sostuvo:

No todas las adherencias de nosotros son buenas. Tenemos que mostrar sólo las buenas, pero tenemos que dejar en claro que, más allá de las buenas adherencias, tomar pastillas es un garrón. La campaña tiene que tener un final feliz: me cuesta, pero ir a la RAJAP me ayudó. (Hugo, entrevista, $28 / 12 / 2015)$

En el marco de los encuentros nacionales se desarrolla también la actividad "adherencia a la vida". Según Melina, se trata de "un momento único de descarga emocional" que busca poner de manifiesto temores, angustias y desafíos vinculados a la vida con la enfermedad.

Otra instancia para abordar las dificultades del tratamiento son los denominados "talleres de adherencia". Durante el trabajo de campo participé de dos: Uno se realizó en la sede de la RAJAP ubicada en el barrio porteño de Balvanera y fue coordinado por médicas infectólogas - Valeria y Mariel - invitadas por los jóvenes. El segundo, fue coordinado por Claudio (32 años, médico comunitario y coordinador nacional de la RAJAP durante 20132014) y se realizó en el marco del "encuentro regional", una actividad que convocó a los integrantes de la provincia de Buenos Aires, ciudad de Buenos Aires y de otras regiones del país durante un fin de semana en un predio del conurbano bonaerense.

Retomando a Hugo, exploro posibles respuestas a las siguientes preguntas: ¿En qué consisten esas "buenas adherencias”? ¿Cuáles no lo son? Y ¿cómo se reconcilia en las actividades de la red ese "mostrar sólo las buenas" con el reconocimiento y la contención de las que "no son buenas"? Sugiero que el análisis de los significados y sentidos de los activistas en torno a los tratamientos de larga duración invita a descentrar el problema de la "adherencia" de la mirada biomédica construida "sobre la base de un modelo del "deber ser" caracterizado por una fuerte marca de responsabilidad individual de las personas frente a la enfermedad y su resolución” (MARGULIES 2014). Frente a esta perspectiva, diversos estudios sobre jóvenes con VIH (ADASZKO 2006; 2012; AGOSTINI et al 2018; BERNAYS et al 2017; MATTES 2014) han señalado la necesidad de entender al tratamiento como parte de procesos de gestión de la enfermedad que sobrepasan el mundo biomédico y abarcan la vida cotidiana y las distintas dimensiones del mundo social (GOOD 1994; PIERRET 2003).

A continuación, analizo las interacciones que se suscitaron durante los "talleres de adherencia" en torno al tratamiento antirretroviral para luego indagar en las tensiones que emergen cuando un activista opta por interrumpir su tratamiento. 


\section{Taller de "adherencia" en la sede de la RAJAP}

El taller se inició con la primera diapositiva de una presentación en Power Point con la palabra "ADHERENCIA" en el centro y en un tamaño que buscaba captar la atención de todos. Una de las médicas explicó que "la adherencia es cuánto cumple uno con el tratamiento" y anticipó que en el taller buscarían responder las siguientes preguntas: “¿Por qué hay que tomar la medicación? ¿Por qué es importante el cumplimiento del tratamiento?”. Las primeras explicaciones se centraron en la acción del virus sobre los mecanismos de defensa del cuerpo. A partir de ilustraciones, mostraron cómo "el virus se reproduce por el cuerpo disminuyendo los linfocitos T de las células CD4 ”. El foco de la presentación de las médicas estuvo en los efectos de la medicación en la replicación viral y en la responsabilidad del paciente frente a las prescripciones médicas.

Las médicas dieron lugar a que los jóvenes expusieran sus inquietudes. Uno de los puntos destacados fue el vínculo entre el alcohol, la marihuana y el TARV. Frente a una pregunta de Nacho (responsable de la "comisión de comunicaciones"), Valeria respondió "las drogas y el alcohol impiden la adherencia. Te desconectan de la realidad. Si con un vaso de cerveza ya estás borracho y no consumís la pastilla al otro día, es un problema grave". Agregó: "La marihuana detiene el sistema inmunitario. Más si es algo constante. Hace que te olvides de tomar las pastillas". Fue entonces que Nacho dijo: "Yo tomo mucho y fumo marihuana, y nunca me olvidé de tomar la pastilla", a lo cual Valeria respondió: "Eso está muy bien. La marihuana, particularmente, no interactúa con la droga”.

La argumentación de Valeria pasó así del problema de la interacción entre drogas, medicamentos y sistema inmunitario a la cuestión del olvido de las dosis, reconociendo que, si esto último no ocurría "entonces, no pasa nada". Este diálogo despertó inquietudes en Damián (activista adolescente), a quien su infectóloga le había indicado que tomara la medicación antes de salir a bailar con el objetivo de no afectar el tratamiento.

Damián: Mi doctora me dijo que tome las pastillas dos horas antes de ir a bailar ¿Esto está bien?

Mariel: Tu doctora debe tener razón porque el alcohol lentifica el trabajo en el hígado.

Si bien la pregunta de Damián no explicitaba el tema del consumo de sustancias, la respuesta de Mariel asumió que "ir a bailar" implicaba tomar alcohol. Fue entonces que Camila (activista) preguntó sobre el "permitido" de alcohol y drogas recreativas y la respuesta de Mariel fue: "El alcohol y las drogas hacen mal al organismo de cualquiera". Pablo (activista y enfermero), insistió en la posibilidad de identificar un "parámetro" o medida de referencia objetiva. 
Tengo una duda objetiva. ¿Cuál es la interacción entre las drogas y los fármacos? Traté de buscar una respuesta. Sin embargo, todavía no encuentro un parámetro, una cantidad. (Pablo).

La respuesta fue: "las cantidades son personales". De nociones universalistas como "el alcohol y las drogas hacen mal al organismo de cualquiera”, se pasa a una visión particularista ("las cantidades son personales") en la que se focaliza en la acción responsable de cada uno a partir de un modelo del "deber ser" marcado por definiciones basadas en el saber biomédico. En las preocupaciones de las médicas se expresa una visión de los jóvenes como sujetos propensos a "olvidar" una dosis luego de consumir alcohol o marihuana. El consumo de alcohol y drogas son constitutivos del ideal de juventud históricamente configurado en Argentina desde los años 1960 (MANZANO 2014). Esas preocupaciones resultan interpeladas a partir de las intervenciones de los jóvenes, quienes despliegan sus propios saberes de la vida con la enfermedad y el tratamiento. En sus respuestas y comentarios ilustran cómo una "buena adherencia" puede asociar una ingesta adecuada de la medicación con el consumo controlado de alcohol y drogas recreativas, demandando, en cambio, al saber biomédico, el establecimiento de una medida numérica, la estandarización de "un parámetro, una cantidad” en la interacción posible entre drogas y fármacos.

\section{"Taller de Adherencia" durante el encuentro regional de la RAJAP}

El "encuentro regional" se realizó con financiamiento de ONUSIDA con el propósito de socializar entre los activistas los resultados de una investigación (DNSyETS 2017) realizada por esta agencia, UNICEF, la RAJAP y la DNSyETS. La RAJAP incluyó esta actividad en el marco de una agenda de dos días. Claudio fue invitado a dictar el "taller de adherencia”. Mostraba diapositivas con preguntas o temas para circular la voz entre el resto. La primera diapositiva abría el espacio con la pregunta: “Qué me preocupa?”. Los jóvenes respondieron: "el cambio de esquemas", "el deterioro del hígado" y "no saber cuál va a ser la próxima medicación". El "manejo de la incertidumbre" (MARGULIES; BARBER; RECODER 2006) sobre la efectividad a largo plazo de los tratamientos y los potenciales efectos adversos se torna una cuestión existencial central para estos jóvenes. "El cambio de esquemas" implica el reemplazo de una asociación de medicamentos por otra abriendo el interrogante sobre una posible falta de esquemas antirretrovirales en el futuro. "El deterioro del hígado" es un efecto asociado al consumo de medicación que conlleva para quienes lo sufren la realización periódica de exámenes para chequear los niveles de bilirrubina, añadiendo un requerimiento adicional a los cuidados.

La siguiente diapositiva propuesta por Claudio fue “¿Qué es salud?”. Para algunos jóvenes la salud se asoció a logros del tratamiento y a mediciones objetivas. Específicamente, se dijo: "la veo ligada a la indetectabilidad" como logro alcanzable mediante el TARV y que, luego de seis meses continuos, disminuye casi al mínimo las posibilidades de transmisión durante una relación sexual desprotegida (DNSyETS 2019b). Otro joven se refirió a "[lo 
gratificante que es] cuando te suben los CD4" como indicador de una buena respuesta inmunitaria.

Otras respuestas destacaron una dimensión emocional: “[es] cuando estoy anímicamente bien", "es algo muy personal ya que quizás uno médicamente no está bien, pero tiene cosas para hacer y se siente bien". Quienes hasta el momento no habían hablado, se expresaron de distintas formas. Uno manifestó su "enojo" respecto a "que tomar las pastillas sea una rutina, como cepillarse los dientes". Otra expuso su "mayor miedo": "No darle un padre a mi hija si me llega a pasar algo".

En el cierre del taller, Claudio propuso "dar nuevos significados a los conceptos" y sugirió "fortalecer para adherir a la vida" recuperando la actividad del "encuentro nacional". Invitó de este modo a reflexionar sobre el problema de reducir la "adherencia” únicamente a la ingesta de la medicación: "tomar las pastillas es [sólo] lo biológico". Claudio ubicó en primer plano las dimensiones afectivas y materiales del tratamiento que pueden ocasionar la interrupción de la ingesta de la medicación: “¿Qué pasa con los compañeros que no tienen trabajo? ¿O con los que tienen problemas en sus familias?”.

En estos términos, la "adherencia" conlleva momentos en los que el tratamiento se interrumpe: "no se puede mantener siempre", señala Claudio, "es como la felicidad, nunca será total y perfecta". Aquí, la "adherencia” es planteada como un proceso que puede implicar la discontinuidad de la ingesta de la mediación. Sin embargo, como se muestra en los extractos, esa discontinuidad se asocia a temores y preocupaciones ante sus eventuales consecuencias somáticas.

\section{Iziel}

El material que se expone es el resultado de la reconstrucción de una parte de la biografía de Iziel a partir de dos entrevistas en profundidad (realizadas el 17/10/2015 y el 07/03/2016).

Durante el trabajo de campo, Iziel tenía 24 años. Había nacido en Moca, una localidad rural de República Dominicana. Migró a Buenos Aires el 1 de junio de 2014 en búsqueda de opciones terapéuticas para el VIH. Joven de piel negra, con fuerte acento centroamericano y definido a sí mismo como "homosexual", Iziel se relacionaba sexualmente con otros varones sin utilizar ningún método de prevención de infecciones de transmisión sexual.

Había tomado conocimiento de su diagnóstico a partir de un "test pre-quirúrgico". Su médico le recomendó entonces que iniciara el tratamiento lo más temprano posible y le transmitió las posibilidades existentes en otros países, ya que "en República Dominicana no había una buena cobertura". Argentina, Estados Unidos y Cuba eran las tres opciones. Iziel eligió Argentina ya que en 2007 había visitado el país y recordaba con agrado su estadía.

Mientras que en República Dominicana la cobertura de los tratamientos para los afectados es limitada y depende del financiamiento externo (OPS, 2012), en Argentina existe desde 2013 "oferta universal" financiada casi en su totalidad por el Estado. La decisión de Iziel de migrar es estructurada a partir de las condiciones limitadas en su contexto de origen 
(FARMER 1996) en donde el tratamiento antirretroviral es solo para algunos o "para quien lo pueda pagar" (CASTRO; FARMER, 2003).

Iziel acudía semanalmente a un hospital del subsistema de salud público de la ciudad de Buenos Aires el cual cuenta con un espacio de consulta psicológica para pacientes con VIH. Tomando la recomendación de su psicóloga, Iziel asistió a la primera reunión de la RAJAP en julio de 2014 y comentó con desagrado ese encuentro sintiéndose diferente por el color de su piel y su vida sexual: "yo era el único que tenía que exponer que me acosté con 20 chabones por día y no sabía lo que era un forro hasta que tuve VIH. Entonces dije para mí mismo: 'Negro, extranjero, y encima esto; no' Por más que me insistieron en que hablara, me fui”.

En mayo 2015, la psicóloga se dio cuenta que Iziel había dejado la medicación. Iziel adjudicó esta interrupción a lo que él denominó "dominican depre": "estaba perdido. Yo me levantaba y no sabía si buscar un trabajo, una escuela, o llamar a casa y decir que quiero volver". Para superar esta situación, su psicóloga le sugirió retornar a la red. Así, en julio de 2015 comenzó a participar en la RAJAP y retomó el tratamiento. Con el tiempo su involucramiento dejó de ser una "opción”: "tengo una dependencia emocional. Cuando no estoy con los chicos o haciendo algo con la red, me caigo fuerte. Este es mi lugar". Eventualmente Iziel pasó a presidir la "comisión de adherencia”.

En noviembre de 2015, nuevamente dejó la medicación argumentando "no sentir tener el virus". En este contexto decía sentirse "dos personas" ya que mientras ayudaba a otros activistas a "que no dejen la medicación", él sí lo hacía. Sin embargo, al referir sus preocupaciones sobre padecimientos que lo aquejaban, manifestó el temor de que "algún día vengan las facturas" desplazando al futuro las consecuencias potenciales de su toma de riesgos en el presente. Como señala Rohden (2018), la pretensión de una "calidad de vida" en el presente, puede no coincidir con la búsqueda de salud a largo plazo.

En febrero de 2016 ingresó a trabajar en el sector de ventas de una compañía de call center. El vínculo con un nuevo grupo de amistades lo llevó a tener interacciones en las que el VIH ya no era el tema central. Mientras que los vínculos con los activistas de la RAJAP le recordaban su condición serológica, con sus compañeros de trabajo hablaba de "cualquier otra cosa".

En relación con su elección de "no tomar la medicación", Iziel me relató con desagrado ciertos momentos en los que otros jóvenes de la RAJAP comunicaban por Facebook haber alcanzado la "indetectibilidad" empleando la consigna internacional "Indetectable=intransmisible".

Algo que sí me está afectando es en el chat del grupo de Facebook: es como algo muy distinto a la realidad. (...). Hay un hashtag nuevísimo del grupo que dice \#indetectablenotransmite. O sea que el que toma la medicación está bien, el que no la toma que se joda. (...) Se siente como feo esto de la felicidad por estar 'indetectable' (Iziel). 
A la vez responsable de la "comisión de adherencia" y él mismo en ocasiones "no adherente", la historia relatada por Iziel, "negro, extranjero", "homosexual” y activista, muestra una trayectoria de atención y cuidados que, lejos de desarrollarse lineal o unívocamente, se encuentra atravesada por "diferentes cursos de acción, vacilaciones, dudas" y el establecimiento de "nuevas redes sociales" (ALVES 2015). Estas abren para él nuevos "lugares" de pertenencia y sociabilidad y simultáneamente producen la segmentación de su vida cotidiana entre la participación en actividades focalizadas en la enfermedad y otras en las que pondría en juego "una identidad no focalizada en el VIH-Sida" que, siguiendo su relato, lo alejaban del tratamiento (MARGULIES; BARBER; RECODER, 2006; TAKAHASHI; WIEBE; RODRÍGUEZ, 2001).

\section{Reflexiones finales}

Hasta aquí describí cómo la cuestión de la "adherencia" a los tratamientos antirretrovirales se presenta y discute en ocasión de eventos y actividades de la RAJAP con la intención de mostrar los diversos sentidos y prácticas que despliegan los activistas. A la vez, este mostrar la diversidad nos aproxima a los límites del discurso dominante que tiende a reducir la "adherencia" a "la actitud racional o irracional del paciente" (MARGULIES; BARBER; RECODER 2006).

La conformación de la RAJAP se corresponde con un contexto de respuestas al VIH marcado por la vigencia de una agenda política global con apoyo financiero orientado a grupos considerados "en riesgo", agenda catapultada desde el año 2000 con los ODM y profundizada con la "acción acelerada" para "poner fin a la epidemia" (ONUSIDA, 2014) mediante la promoción de la "adherencia", entre otras estrategias. La legitimidad de estas políticas y metas globales es "socialmente producida" (FASSIN 2005) a partir de un discurso médico e información epidemiológica (Naciones Unidas 2010; OMS 2010). En la RAJAP está "bio-legitimidad" (FASSIN 2004) es revindicada y apropiada, abriendo el camino a oportunidades de financiamiento, por los cuales los activistas han ido optando estratégicamente, orientando las actividades a las cuales destinar los recursos económicos: encuentro nacional, reuniones regionales, entre otras.

En la Argentina esta agenda global se inscribe en procesos previos de organización de las respuestas sanitarias centradas en la acción estatal y que, desde mediados de la década de 1990, consolidaron el rol central de las organizaciones de personas viviendo con VIH en la respuesta nacional a la epidemia, la promoción de derechos y en acciones de prevención. Entre estas, proyectos financiados y supervisados por organismos multilaterales como los "programas de educación inter pares".

La centralidad de la "adherencia" en las acciones de la RAJAP se inscribe en un contexto local en el cual la promoción del tratamiento no sólo busca reconstruir el sistema inmunológico de los afectados, sino también reducir las probabilidades de su transmisión en relaciones sexuales sin preservativo. Así, la meta de la "indetectabilidad”, construida sobre la 
responsabilidad individual, se presenta como una de las principales estrategias de prevención colectiva.

Cuando, en el marco de la campaña publicitaria financiada por una ONG de Estados Unidos, Hugo plantea "mostrar sólo las buenas [adherencias]" presentando testimonios de jóvenes que han alcanzado la "indetectabilidad", en este "mostrar" está implicada la orientación esperada de las actividades "comunitarias" articuladas con las prioridades sanitarias y políticas relativas al poner fin a la epidemia (GREGORIC 2008). También mostrar los casos de "indetectabilidad" en "Te cuento mi adherencia" tiene que ver con las condiciones y resultados esperados por las agencias y programas que apoyaron estas actividades.

Como hemos descripto, los jóvenes mantienen una actitud parcialmente confrontativa con el discurso médico sobre la medicación. En el taller realizado en la sede de la RAJAP, la ingesta ininterrumpida de la medicación se reproduce como un horizonte compartido por jóvenes y médicas. En cambio, los jóvenes desafían las pautas establecidas respecto del consumo de alcohol y drogas recreativas, cuestionan la asociación entre baileconsumo de alcohol-olvido de dosis, aunque buscando la certificación "experta" para conciliarlo con la ingesta de la medicación.

En el taller de Claudio, se admite y comparte la posibilidad de interrumpir el tratamiento y retomarlo después, aunque, al mismo tiempo, se expresan temores y preocupaciones ante sus eventuales consecuencias. Los jóvenes cavilan en torno de los efectos del tratamiento en el cuerpo, comparten emociones (miedo, enojo) y, con este encuadre, emerge la consigna "adherir a la vida" y la necesidad de las acciones de "contención" y acompañamiento más allá de las cuestiones estrictamente "médicas".

En las propuestas programáticas de la RAJAP tienen una fuerte presencia el discurso y las nociones médicas sobre los tratamientos y sus requisitos. En la comisión y los talleres de "adherencia" es posible captar esa orientación normativa al abordar las dificultades e incertidumbres de los activistas para llevar a cabo sus tratamientos. En esos dispositivos vemos a la vez el esfuerzo por compartir y aclarar información y también por acompañar y "contener" las vicisitudes de la vida con la enfermedad.

Finalmente, en el relato de Iziel sobre su trayectoria como activista, y él mismo responsable de la comisión de "adherencia", podemos encontrar los límites de las acciones de "contención" entre "pares" para garantizar una "buena adherencia” o para retomar el tratamiento cuando éste es interrumpido. En sus respuestas, Iziel pone incluso en evidencia cómo el énfasis programático en mostrar e intercambiar trayectorias exitosas de "indetectabilidad", en línea con la campaña global "I=I", puede resultar estigmatizante para quienes -como él- no logran adecuarse al modelo establecido de cumplimiento o comportamiento adecuado. En sus vacilaciones y dudas, también en sus certezas y sus enojos, el discurso de Iziel interpela no sólo la orientación normativa sino también la amenaza de sanción moral. 


\section{Referencias bibliográficas}

ADASZKO, Ariel. (2006). De tomar pastillas a saberse viviendo con VIH/Sida. Trayectorias de vida y reflexividad de jóvenes que crecieron viviendo con VIH/Sida desde niños. En: Actas de las IV Jornadas de Investigación en Antropología Social, Facultad de Filosofía y Letras, Universidad de Buenos Aires. Buenos Aires.

ADASZKO, Ariel. (2012). "Trayectorias de vida y manejo de la enfermedad en la vida cotidiana de adolescentes que crecieron viviendo con VIH/Sida”. En: Actualizaciones en Sida. vol. XII, N 75, pp. 19-32.

AGOSTINI, Rafael; MASKUD, Ivia; FRANCO, Túlio. (2018). "Eu tenho que te contar um negócio”: gestão da soropositividade no contexto dos relacionamentos afetivo-sexuais de jovens vivendo com HIV”. En: Sexualidad, Salud y Sociedad Revista Latinoamericana. Rio de Janeiro: N²9, pp.201-223. DOI: http://dx.doi.org/10.1590/1984-6487.

ALVES, Paulo Cesar. (2015). Itinerário terapêutico e os nexus de significados da doença. En: Política \& Trabalho Revista de Ciências Sociais. Paraíba: No 42, pp. 29-43.

ARGENTINA. (1990). Ley N23.798 de 16 de agosto de 1990 - Declárase de interés nacional a la lucha contra el sindrome de inmunodeficiencia adquirida. CABA: Senado y Cámara de Diputados de la Nación.

ARGENTINA. (2003). Ley N25.673 del 23 de mayo de 2003 - sobre Salud Sexual y Procreación Responsable. CABA: Senado y Cámara de Diputados de la Nación.

ARGENTINA. 2006. Ley N 26.150 de 4 de octubre de 2006 - educación sexual integral. CABA: Senado y Cámara de Diputados de la Nación.

ARGENTINA. (2010). Ley N²6.618 del 15 de julio de 2010 - modificación del código civil. CABA: Senado y Cámara de Diputados de la Nación.

ARGENTINA. (2012). Ley N 26.743 del 9 de mayo de 2012 - derecho a la identidad de género de las personas. CABA: Senado y Cámara de Diputados de la Nación.

BALBI, Fernando. (2010). "Perspectivas en el análisis etnográfico de la producción social del carácter ilusorio del Estado”. En: Revista de Estudios Marítimos y Sociales. Mar del Plata: $\mathrm{N}^{\circ}$ 3, pp.171-179.

BIAGINI, Graciela; SANCHEZ, Marita. (1995). Actores sociales y SIDA. ¿Nuevos movimientos sociales? ¿Nuevos agentes de salud? Las organizaciones No Gubernamentales y el complejo VIH/SIDA. Buenos Aires: Espacio Editorial.

BIAGINI, Graciela. (2009). Sociedad civil y VIH-sida: ¿de la acción colectiva a la fragmentación de intereses? Buenos Aires: Ediciones Paidós.

BERNAYS, Sarah; PAPARINI, Sara; SEELEY Janet; RHODES Tim. (2017). "Not taking it will just be like a sin': young people living with hiv and the stigmatization of less-thanperfect adherence to antiretroviral therapy". En: Medical Anthropology Journal, CrossCultural Studies in Health and Illness. Reino Unido: Vol N³6, pp. 485-499. DOI: https://doi.org/10.1080/01459740.2017.1306856. 
CASTRO, Arachu; FARMER, Paul. (2003). "El Sida y la violencia estructural: La culpabilización de la víctima”. En: Cuadernos de Antropología Social. CABA: n¹7, pp. 29-47.

CHAVES, Mariana. (2010). Jóvenes, territorios y complicidades. Una Antropología de la juventud urbana. Espacio Editorial. Buenos Aires.

CLARKE, Adele; SHIM, Janet; MAMO, Laura; FOSKER, Jennifer Ruth; FISHMAN, Jennifer. (2010). "Biomedicalization: Technoscientific Transformations of Health, Illness, and U.S. Biomedicine”. En: American Sociological Review. Online: V 68, n². DOI: https://doi.org/10.2307/1519765

CSSSeI. (2018). En equipo. Publicación de la Coordinación de Salud Sexual, SIDA e ITS. Buenos Aires.

COLAUTTI, Marisel Andrea. (2012). "Las personas que viven con VIH/SIDA y su vínculo con los antirretrovirales provistos por el Programa Nacional en Argentina”. En: Revista Ciência \& Saúde Coletiva. Rio de Janeiro: N¹7. DOI: https://doi.org/10.1590/S141381232012000500014.

DNSyETS. (2015). Boletín sobre VIH-SIDA en Argentina. CABA: vol XVIII, No 32.

DNSyETS. (2017). Jóvenes con diagnóstico reciente de VIH en el Área Metropolitana de Buenos Aires. CABA.

DNSyETS. (2019a). Boletín sobre VIH-SIDA en Argentina. CABA: Vol XXII, № 36.

DNSyETS. (2019b). Indetectable=Intransmisible. Ausencia de transmisión sexual del VIH en personas bajo tratamiento antirretroviral y con carga viral indetectable. CABA.

DNSyETS. (2019c). Proyecto piloto de implementación de centros de prevención combinada y PrEP en la República Argentina: Guía de Directrices clínicas para equipos de salud. CABA.

FARMER, Paul. (1996). "On Suffering and Structural Violence: A View from Below”. En: Daedalus. MIT Press. Cambridge: V 125, n¹, pp. 261-283.

FASSIN, Didier. (2004). "Entre las políticas de lo viviente y las políticas de la vida. Hacia una antropología de la salud”. En: Revista Colombiana de Antropología. Bogotá: V 40, pp. 283-318. DOI: https://doi.org/10.22380/2539472X.1226

FASSIN, Didier. (2005). "Le sens de la santé". En: Anthropologie médicale. Ancrages locaux, défis globaux (dir SAILLANT, Francine y GENEST, Serge). Anthropos. París.

GOOD, Byron. (1994). "El cuerpo, la experiencia de la enfermedad, y el mundo vital: una exposición fenomenológica del dolor crónico”. En: Medicina, Racionalidad y Experiencia. Una Perspectiva Antropológica. Barcelona: Ediciones Bellaterra.

GREGORIC, Juan. (2007). VIH-SIDA y activismo: Un estudio antropológico del proceso de organización y la politización de la salud entre personas viviendo con el VIH. Tesis de Licenciatura. Facultad de Filosofía y Letras Universidad de Buenos Aires.

GREGORIC, Juan. (2008). Entre 'la parte social' y 'lo que tiene que ver con políticas'. Una aproximación a las acciones y demandas de personas que viven con VIH-SIDA de sectores populares. Trabajo presentado en: IX Congreso Argentino de Antropología Social, 
Facultad de Humanidades y Ciencias Sociales, Universidad Nacional de Misiones. Posadas.

GREGORIC, Juan. (2016). "Entre biosocialidad y biolegitimidad: Socialidad, tratamiento y activismo en una asociación de personas que viven con VIH”. En: REDES, Revista de Estudios Sociales de Ciencia. Bernal: V 22, n42, pp 109-132.

GRIMBERG, Mabel. (2003). "Narrativas del cuerpo. Experiencia cotidiana y género en personas que viven con VIH”. En: Cuadernos de Antropología Social. CABA: Vol 17, Nº1.

KROPFF, Laura. (2010). “Apuntes conceptuales para una antropología de la edad”. En: Avá, Revista de Antropología. Misiones: n¹6.

MANZANO, Valeria. (2014). "Política, cultura y el 'problema de las drogas' en la Argentina, 1960-1980s”. En: Apuntes de investigación del CECYP. Buenos Aires: V 17, n²4, pp. 51 78.

MATTES, Dominik. (2014). "'Life is not a rehearsal, it's a performance': An ethnographic enquiry into the subjectivities of children and adolescents living with antiretroviral treatment in northeastern Tanzania”. En: Children and Youth Services Review. Online: $\mathrm{N}^{\circ} 45$, pp.28-37. DOI: https://doi.org/10.1016/j.childyouth.2014.03.035

MARGULIES, Susana. (2014). La atención médica del VIH-Sida. Un estudio de antropología de la medicina. CABA: Editorial Facultad de Filosofía y Letras, Universidad de Buenos Aires.

MARGULIES, Susana; BARBER, Nélida; RECODER, María Laura. (2006). "VIH-SIDA y adherencia al tratamiento. Enfoques y perspectivas”. En Antípoda: Revista de Antropología y Arqueología. Bogotá: Universidad de Los Andes. N³, pp 281-300. DOI: https://doi.org/10.7440/antipoda3.2006.11.

NACIONES UNIDAS. (2010). Objetivos de Desarrollo del Milenio Informe 2010. Nueva York. OMS. (2010). Proyecto de estrategia OMS contra el VIH/sida para 2011-2015. Ginebra.

OPS. (2012). Tratamiento antirretroviral bajo la lupa: un análisis de salud pública en Latinoamérica y el Caribe. Washington. D.C.

ONUSIDA. (2000). Educación Inter Pares y VIH/SIDA. Conceptos, usos y problemas. Ginebra.

ONUSIDA. (2014). 90-90-90 Un ambicioso objetivo de tratamiento para contribuir al fin de la epidemia de sida. Ginebra.

ONUSIDA. (2015). Fast-tracking combination prevention: Towards reducing new HIV infections to fewer than 500.000 by 2020 . Ginebra

ONUSIDA. (2016). Acción acelerada para acabar con el SIDA. Ginebra.

PECHENY, Mario; MANZELLI, Hernán; JONES, Daniel. (2002). "Vida cotidiana con VIH/SIDA y/o con hepatitis C: diagnóstico, tratamiento y proceso de expertización”. En: CEDES/Cuaderno del Ciclo de Seminario de Salud y Política Pública. Buenos Aires.

PECHENY, Mario. (2016). Carlos Jauregui y la ciudadanización sexual. En: Acá estamos: Carlos Jauregui, sexualidad y política en la Argentina. CABA: Legislatura de la Ciudad Autónoma de Buenos Aires. 
PIERRET, Janine. (2003). “The illness Experience: State of Knowledge and Perspective for Research". En: Sociology of Health and Illness. Online: V 25, pp.4-22. DOI: https://doi.org/10.1111/1467-9566.t01-1-00337.

RABINOW, Paul. (1996). Essays on the Anthropology of Reason. Princeton. Princeton University Press.

ROHDEN, Fabiola. (2018). "Os hormônios te salvam de tudo": produção de subjetividades e transformações corporais como uso de recursos biomédicos. En: Mana. Vol.24, n. 1, pp. 199-229. DOI: https://doi.org/10.1590/1678-49442018v24n1p199.

ORIOL ROMANÍ, Alfonso; CASADÓ I MARIN, Lina. (2014). Jóvenes, desigualdades y salud: Vulnerabilidad y políticas públicas. Publicaciones de la Universitat Rovira i Virgili.

TAKAHASHI, Lois; WIEBE, David; RODRÍGUEZ, Ricardo. (2001). Navigating the TimeSpace Context of HIV and AIDS: Daily Routines and Access to Care. En: Social Sciences \& Medicine. Online: V 53, pp.845-863. DOI: 10.1016/S0277-9536(00)00363-4

UNICEF. (2019). Seguimiento por el UNICEF de las recomendaciones y decisiones de las

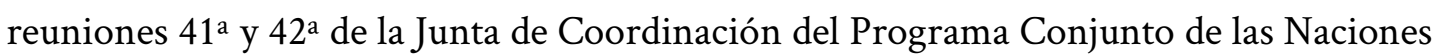
Unidas sobre el VIH/SIDA.

VALLE, Carlos Guilherme. (2013). Doença, ativismo biossocial e cidadania terapêutica: a emergência da mobilização de pessoas com HIV no Brasil. En: Vivência. Revista de Antropologia. Rio Grande do Norte: V 1, n41, pp. 41-76.

VALLE, Carlos Guilherme. (2015). Biosocial Activism, Identities and Citizenship: Making up 'people living with HIV and AIDS' in Brazil. En: Vibrant: Virtual Brazilian anthropology. Online: V 12, n². DOI: https://doi.org/10.1590/180943412015v12n2p027.

\section{sobre el autor}

\section{Tomas Kierszenowicz}

Becario doctoral CONICET para el Programa de Antropología y Salud de la Facultad de Filosofía y Letras, Programa Antropología y Salud de la Universidad de Buenos Aires. Licenciado en ciencias antropológicas. Profesor de enseñanza media y superior en ciencias antropológicas.

Fecha de recepción 03/07/2020

Fecha de aprobación 21/12/2020 